\title{
The Outcomes of Thirsty? Choose Water! A Randomised Controlled Trial to Determine The Effects of A Behavioural and an Environmental Intervention on Water and Sugar Sweetened Beverage Consumption in Adolescents.
}

\author{
Nicole Kajons \\ Central Coast Local Health District \\ Michael David \\ University of Queensland \\ Justine Gowland-Ella \\ Central Coast Local Health District
}

Samantha Batchelor ( $\square$ samantha.batchelor@health.nsw.gov.au )

Central Coast Local Health District https://orcid.org/0000-0002-0926-8113

Peter Lewis

Central Coast Local Health District

\section{Research article}

Keywords: Randomised controlled trial, Health Promoting Schools, School intervention, Obesity, Water consumption, Sugar sweetened beverages, Chilled water stations

Posted Date: October 5th, 2020

DOI: https://doi.org/10.21203/rs.3.rs-73652/v1

License: (c) (i) This work is licensed under a Creative Commons Attribution 4.0 International License. Read Full License 


\section{Abstract}

Background: Childhood obesity is a serious public health challenge in Australia, with approximately one in four (24.9\%) children aged 5-17 years being overweight or obese. Sugar sweetened beverages are one contributing factor and detrimental to health. Adolescents are the highest consumers of these, with nearly $25 \%$ of NSW children aged 12-17 years consuming sugar sweetened beverages at least 5 or more times per week. This study aims to address this by encouraging adolescents to choose water instead of sugar sweetened beverages and determine the effectiveness of two interventions (one behavioural and one environmental) alone or combined in achieving this outcome.

Methods: An open-label randomised controlled trial utilising a two-by-two factorial design recruited 61 schools from across three Local Health Districts in NSW, Australia, randomising them to one of four study arms: a behavioural intervention, an environmental intervention, both or neither. Student surveys, school level surveys and water flow measurement data was collected. The primary outcome was increased water consumption, with secondary outcomes including changes in SSB consumption. To quantify the individual and joint effects of the interventions on the consumption of water and SSBs, random effects multivariable ordinal logistic regression models were derived for each outcome.

Results: For students receiving at least one intervention there was an increased odds (though not statistically significant) of higher water consumption compared to those that received no intervention; whilst there was a statistically significant decrease in SSB consumption for students who received both interventions combined $(\mathrm{OR}=.67 ; 95 \%$ confidence interval, $0.55-.082 ; \mathrm{P}<0.01)$.

Conclusions: Evidence regarding school based obesity prevention continues to emerge, however, to our knowledge this is the first Australian study focussed on examining effective school-based interventions to specifically promote the consumption of water and decrease the consumption of SSBs in adolescents. The combination of a behavioural and an environmental intervention had a greater effect on decreasing SSB consumption. This is noteworthy given SSBs are a key contributor to overweight and obesity. The delivery of these combined interventions in schools can add value to existing interventions that address the complex public health issue of overweight and obesity.

Trial Registration: Australian and New Zealand Clinical Trials Register ACTRN12618000526279 10 April 2018

http://www.anzctr.org.au/Trial/Registration/TrialReview.aspx?ACTRN=12618000526279

\section{Background}

Overweight and obesity among children and adolescents is a major public health issue, with approximately one in four Australian children above a healthy weight. ${ }^{1}$ Among the many contributing factors to this is the consumption of sugar sweetened beverages (SSBs), including soft drinks, energy drinks, fruit drinks, sports drinks and cordial. These beverages are energy dense, provide little or no nutritional value and contribute to excessive sugar intake. A recent review of the impacts of SSBs on children and adolescents showed clear and consistent evidence that SSBs contribute to weight gain and obesity, strong evidence of a link to dental caries, and a link to the development of insulin resistance. An association was also demonstrated between caffeinated SSBs, such as energy drinks, and their impact on a range of health issues including poor quality or reduced sleep, headaches, risk-seeking behaviour and depressive symptoms. ${ }^{2}$

International data shows that adolescents are generally high consumers of SSBs, resulting in an intake of free sugars higher than that recommended by the WHO. ${ }^{3}$ Australian data is consistent with this, with adolescents being the highest consumers of SSBs. The most recent National Health Survey results showed that 585 of children aged 12-13 years consumed SSBs at least once a week ${ }^{1}$, and the 2012-13 National Secondary Students' Diet and Activity survey showed that $14 \%$ of students are high soft drink consumers, consuming four or more cups each week. ${ }^{4}$ In NSW on most days of the week, nearly $25 \%$ of children aged 12-17 years consume the equivalent of at least 1.5 glasses of soft drink or other SSBs. ${ }^{5}$ Considering the negative health effects of SSBs and their high consumption amongst adolescents, it is imperative that effective interventions to address these consumption levels are identified and implemented.

In recent years there has been growing evidence regarding strategies to reduce SSBs consumption and increase water consumption in school settings. Schools are often identified as key settings for health promotion, given their reach to adolescents and the amount of time young people spend there. ${ }^{6}$ Increasing water consumption has been identified as an important factor, with evidence suggesting that the displacement of SSBs with increased consumption of water can have positive impacts on overweight and obesity. 8 In addition to having a potentially positive impact on weight status, water is free, hydrates the body, contains no kilojoules and has been shown to improve cognition in students, improving attention and memory and assisting with learning. ${ }^{9}$ Data shows adolescents' daily water consumption is, however, below recommended levels in several countries including Australia. ${ }^{10}$

Several systematic reviews have examined strategies to promote water and reduce SSB consumption among children and adolescents, with a range of educational/behavioural, legislative and environmental interventions trialled. 
A 2019 review of 15 interventions to increase water consumption showed that overall, $63 \%$ of interventions reported a significant increase in water consumption; with over half of these interventions including educational/behavioural components. ${ }^{10}$ Whilst evidence suggests that increasing water consumption can have an impact on SSB displacement, a 2020 review of 17 studies utilising water promotion as the primary intervention showed that water promotion alone did not reduce SSB consumption. Of six studies that increased water consumption, only three also reduced SSBs consumption, and conversely, three studies showed decreased SSB consumption, despite no increase in water consumption. The authors thus identified a need for further investigation into studies that combine both water promotion and SSB reduction strategies. $^{11}$

Rhaman et al (2017) reported on 12 school based interventions, which included educational components, lesson delivery, and alternate water sources. They concluded that when compared to no intervention, these interventions had an impact on reducing SSB intake which approached statistical significance $(p=0.06) .{ }^{12}$ Similarly, Vezina-Im $(2017)$ demonstrated a positive effect on decreasing SSB consumption in over $70 \%$ of school-based interventions, regardless of whether the intervention focussed in the individual, the school environment or both. ${ }^{13}$ Vargas-Garcia et al (2017) also found SSB intake in adolescents was significantly reduced with school-based interventions, but the effect size was small. ${ }^{14}$

Of note, each of these systematic reviews called for further studies that utilise stronger study designs including randomised controlled trials, validated self-report data and objective measures, longer term follow-up and the capacity to determine the individual or combined effects of interventions. ${ }^{10-12}$ Furthermore, of the studies included in these systematic reviews only three were Australian studies, of which two were conducted in secondary schools. Both these studies addressed broader healthy eating/physical activity interventions, which demonstrated a positive effect on SSB consumption. This shows limited evidence exists in the Australian context of how to increase water and decrease SSB consumption in adolescents.

The Thirsty? Choose Water! Study addresses this gap by utilising a strong study design and testing both a behavioural and an environmental intervention either alone or combined. The behavioural intervention aligns with the health promoting schools framework, ${ }^{15}$ with evidence showing that school-based interventions delivered utilising this framework show positive effects. ${ }^{6}$ The environmental intervention addresses the issue of access to clean, fresh, chilled water. Numerous studies have identified that suitable water availability in schools is often limited or underutilised, ${ }^{16}$ and that students perceive tap water/bubblers to be unsafe, unhygienic and unpalatable. ${ }^{9,17,18}$ The study overall aimed to determine the effectiveness of the two interventions, either alone or combined, on the primary outcome of increasing water consumption in year 7 secondary students, and the secondary outcomes of effecting changes in students' knowledge, attitudes and behaviour regarding SSBs. This paper reports on the effects of the interventions on water and SSB consumption.

\section{Methods}

\section{Study design and participants}

The Thirsty? Choose Water! Study was a secondary school-based intervention conducted as a randomised controlled trial with a two-by-two factorial design. Two interventions (one behavioural and one environmental) alone and in combination were tested to determine their impact on the primary outcome of increasing water consumption in year 7 students and the secondary outcomes of changing knowledge, attitudes and consumption of SSBs; and changes in the school environment to promote water. A factorial design allowed the effects of both interventions within the same study to be tested and to explore interactions between the interventions, and increase statistical power. Full details of the study design, sample size, power calculations, setting, sample, eligibility, recruitment and study participation and interventions design are detailed in the study protocol paper. ${ }^{19}$ Ethics approval was obtained through the Hunter New England Human Research Ethics Committee (17/08/16/4.07), the NSW Department of Education (SERAP2017457) and Broken Bay, Sydney and Wollongong Catholic Diocese and study procedures were approved.

Sixty-one secondary schools (Government, Independent and Catholic) within the boundaries of three NSW Local Health Districts (LHDs) were recruited to the study in late 2017 /early 2018 , through the study project officers. Randomisation occurred at the school level, whereby the study statistician utilised a computerised random number generator to allocate schools to one of the four study arms. Following allocation to study group, all schools participated in baseline data collection in early 2018 . Students and schools were not blinded to the group they were allocated, given the type of interventions trialled. The power and sample size calculation identified that 6370 year 7 students would need to be recruited to the study, to detect a change of $5 \%$ or more in the primary outcome measure, being increased water consumption. At the commencement of the study $72 \%(n=6531)$ of eligible students $(n=8992)$ completed baseline data collection, reducing to $62 \%$ postintervention and $58 \%$ at follow-up.

\section{Intervention}


The two intervention components implemented are described below.

The Behavioural intervention - The TCW-BI aligned with the Health Promoting Schools Framework (HPSF) ${ }^{15}$ and consisted of three components including teaching, promotional and vaccination interventions. The teaching intervention aligned with the NSW Stage 4 PDHPE curriculum and included two 'Thirsty? Choose Water!' lessons delivered within PDHPE to educate students on the key messages regarding water and SSBs. This was reinforced through the promotional intervention utilising school newsletters, social media, posters and other promotional materials which displayed the 'choose water' message, including 'toilet talkers' (info-graphics on toilet doors), hi-vis vests worn by teachers and posters/flip charts at the canteen. The vaccination intervention was delivered during the school-based vaccination program, where the messages were delivered during the clinic through pull-up banners in the clinic area, a distractor card used by the nurse during the administration of the vaccination and the "Spouts and Straws" board game that students played in the standard 15 minutes post-vaccination waiting time. A paper with the full description of the TCW-BI, its acceptability and standalone outcomes is currently under review.

The Environmental intervention - The environmental intervention included the installation of one CWS in all schools allocated to receive this intervention. Following extensive research, a stainless steel wall-mounted station with a chilled drinking fountain, bottle refill capacity and bottle refill counter were identified for installation. Project Officers worked with the intervention schools to determine the most suitable position for the CWS, allowing the greatest access point for year 7 students, and installation occurred following baseline data collection. To promote the CWS to students a large promotional sticker was positioned near the CWS. A full description of the CWS intervention, acceptability and outcomes is currently under review.

\section{Data Collection}

Student surveys: These were completed at three time points: baseline (Term 1, 2018), post-intervention (following delivery of the TCW-BI and/or CWS installation - Term 3 and 4, 2018) and at follow-up, as students commenced year 8 (Term 1, 2019). The survey included validated questions from the NSW Schools Physical Activity and Nutrition Survey (SPANS) ${ }^{20}$ regarding students' beverage consumption, where they purchased beverages and how often SSBs were available in their home, as well as numerous questions designed to reflect knowledge taught through the TCW-BI, including the effects of SSBs and dehydration. Students were also asked about their water consumption, whether they took a drink bottle to school, where they filled it and bubbler usage. Student surveys were predominantly completed utilising an online survey tool within PDHPE lessons. Some schools experienced difficulties accessing the online survey tool, and therefore completed a paper-based version of the survey.

Water Flow Measurement: At CWS installation a data logger and separate water meter were fitted to measure water flow from the in-built bubbler and bottle-filler of the CWS. The data logger measured water flow remotely and continuously in real-time and was installed for one year to capture water flow across four seasons. Data were downloaded to an online portal that researchers and schools could access.

School level data: School level data was collected from key school contacts via an online survey at baseline and follow-up. Variables of interest included school type (e.g. Government, Independent or Catholic), school size (total number and composition of students), the Index of Community Socio-Educational Advantage (ICSEA) (an index of educational advantage or disadvantage), availability of vending machines, the closest access point to sources of SSBs external to the school measured in walking distance, available drinking water sources for students, how water was promoted as the preferred drink of choice and feedback on CWS installation and usage.

\section{Procedures}

Consent for study participation was at the school level and provided by the school principal. Student participation in the study evaluation was through an opt-out process, whereby parents/carers were advised to provide written documentation to the school if they did not wish for their child to participate in the student surveys (with the exception of one Catholic Diocese, which requested an opt-in process, which was adhered to for those schools). A Project Officer in each LHD worked closely with schools to advise them of research processes, timeframes and study requirements. Project Officers also provided relevant training to teachers and immunisation teams who delivered the TCW-BI, and worked with schools on the installation of CWSs.

\section{Data analysis}

All statistical analyses were conducted with Stata V16.0 (StataCorp, College Station, Texas, USA). Frequency counts and percentages were used to describe study data. Employing a 2x2 factorial design, random-effects ordinal logistic regression modelling was used to estimate the main effects of BI (no, yes), CWS (no, yes). In addition, this approach not only allowed for the estimation of accompanying interaction, but also utilised all sample observations by not adopting a complete-case analysis, which would have only included students on the condition that they had provided information at all time-points. To control for confounding and ensure all models were parsimonious, a two-stage screening process was undertaken. Variables with a univariable p-value $<0.05$ were further assessed for model inclusion using a manual 
stepwise backward elimination approach ( $p \geq 0.05$ for removal). To account for a lack of independence when students were observed at multiple time-points, a variance estimator was used to cluster observations from the same individual. For each multivariable model, the proportional odds assumption was assessed using the Brant test. ${ }^{21}$ The presence of multicollinearity and model specification were tested respectively by the variance inflation factor (VIF), and the Pregibon link test. ${ }^{22}$ For each model, unadjusted and adjusted odds ratios (ORs) with 95\% confidence intervals (Cls) were calculated. Due to the presence of heterogeneity in the implementation of BI and CWS, intervention effects are reported only for change between baseline and follow-up. The level of statistical significance for all two-sided tests was set at $5 \%$.

\section{Results}

As shown in Fig. 1, 61 schools from 155 eligible schools across the three LHDs agreed to participate in the study. Of these, the majority were Government schools from New South Wales Department of Education ( $n=42,69 \%)$ followed by Independent schools ( $n=13,21 \%)$ and then by Catholic schools $(n=6 ; 10 \%)$. Participation rates were $73 \%(n=6,531), 63 \%(n=5,620)$ and $58 \%(n=5,215)$ respectively at baseline, postintervention and at follow-up. Amongst the four groups, survey participation rates at the three time-points were consistently higher among students receiving $\mathrm{BI}$, either with CWS or without.

Tables 1 and 2 present the descriptive statistics for school and student-level variables across the four intervention groups. Whilst there were no statistically significant differences between the groups concerning school-level variables, this was not the case for all student-level variables. The proportion of Aboriginal and Torres Strait Islander students in the BI + CWS group $(11 \% ; n=170)$ was significantly $(p<0.01)$ higher than the other three study groups. Additionally, the proportion of males was significantly $(p<0.01)$ higher than females in the BI group (60\% vs $40 \%)$ and the CWS group (57\% vs $43 \%)$. 
Table 1

School-level characteristics at baseline $(\mathrm{N}=61)$

\begin{tabular}{|c|c|c|c|c|c|}
\hline & $\begin{array}{l}\mathrm{BI} \\
(\mathrm{N}=15) \\
\mathrm{n}(\%)\end{array}$ & $\begin{array}{l}\text { CWS } \\
(N=16) \\
n(\%)\end{array}$ & $\begin{array}{l}\mathrm{BI}+\mathrm{CWS} \\
(\mathrm{N}=15) \\
\mathrm{n}(\%)\end{array}$ & $\begin{array}{l}\text { Control } \\
(\mathrm{N}=15) \\
\mathrm{n}(\%)\end{array}$ & P-value ${ }^{a}$ \\
\hline \multicolumn{6}{|c|}{ Designated Year 7 playground } \\
\hline No & $11(73)$ & $11(73)$ & $8(57)$ & $10(77)$ & 0.70 \\
\hline Yes & $4(27)$ & $4(27)$ & $6(43)$ & $3(23)$ & \\
\hline \multicolumn{6}{|l|}{ Distance to nearest shop } \\
\hline$<500 \mathrm{~m}$ & $8(53)$ & $7(47)$ & $2(14)$ & $2(15)$ & \\
\hline $500 m-999 m$ & $2(13)$ & $3(20)$ & $6(43)$ & $5(38)$ & 0.19 \\
\hline $1000 m+$ & $5(33)$ & $5(33)$ & $6(43)$ & $6(46)$ & \\
\hline \multicolumn{6}{|l|}{ LHD } \\
\hline LHD-1 & $5(33)$ & $5(31)$ & $5(33)$ & $5(33)$ & \\
\hline LHD-2 & $5(33)$ & $7(44)$ & $5(33)$ & $6(40)$ & 1.00 \\
\hline LHD-3 & $5(33)$ & $4(25)$ & $5(33)$ & $4(27)$ & \\
\hline \multicolumn{6}{|l|}{ School canteen } \\
\hline Parent or school-operated & $7(47)$ & $6(40)$ & $10(71)$ & $8(62)$ & 0.34 \\
\hline Neither & $8(53)$ & $9(60)$ & $4(29)$ & $5(38)$ & \\
\hline \multicolumn{6}{|l|}{ School type } \\
\hline Public school & $9(60)$ & $12(75)$ & $10(67)$ & $9(60)$ & 0.78 \\
\hline Private school & $6(40)$ & $4(25)$ & $5(33)$ & $6(40)$ & \\
\hline \multicolumn{6}{|l|}{ ICSEA } \\
\hline$<965$ & $5(33)$ & $4(25)$ & $6(40)$ & $5(33)$ & 0.94 \\
\hline $965-1014$ & $4(27)$ & $7(44)$ & $5(33)$ & $4(27)$ & \\
\hline $1015+$ & $6(40)$ & $5(31)$ & $4(27)$ & $6(40)$ & \\
\hline \multicolumn{6}{|l|}{ Vending machines } \\
\hline No & $14(93)$ & $13(87)$ & $14(100)$ & $10(77)$ & 0.24 \\
\hline Yes & $1(7)$ & $2(13)$ & $0(0)$ & $3(23)$ & \\
\hline \multicolumn{6}{|l|}{ Chilled water stations } \\
\hline No & $12(80)$ & $10(71)$ & $13(93)$ & $8(62)$ & 0.26 \\
\hline Yes & $3(20)$ & $4(29)$ & $1(7)$ & $5(38)$ & \\
\hline \multicolumn{6}{|c|}{ Water consumption promoted } \\
\hline No & $1(7)$ & $2(13)$ & $1(7)$ & $4(27)$ & 0.45 \\
\hline Yes & $14(93)$ & $14(88)$ & $14(93)$ & 11(73) & \\
\hline \multicolumn{6}{|l|}{ Water bubblers ( $n=53$ ) } \\
\hline$<10$ & $6(40)$ & $3(23)$ & $3(25)$ & $1(8)$ & 0.48 \\
\hline $10-19$ & $3(20)$ & $6(46)$ & $5(41)$ & $5(38)$ & \\
\hline
\end{tabular}

a P-values calculated by Fisher's Exact Test 


\begin{tabular}{|l|lllll|}
\hline & BI & CWS & BI+CWS & Control & P-value $^{\text {a }}$ \\
& $(\mathrm{N}=15)$ & $(\mathrm{N}=16)$ & $(\mathrm{N}=15)$ & $(\mathrm{N}=15)$ & \\
& $\mathrm{n}(\%)$ & $\mathrm{n}(\%)$ & $\mathrm{n}(\%)$ & $\mathrm{n}(\%)$ \\
\hline $20+$ & $6(40)$ & $4(31)$ & $4(33)$ & $7(54)$ \\
\hline \multicolumn{2}{|l|}{ a P-values calculated by Fisher's Exact Test } & & \\
\hline
\end{tabular}

Table 2

Student-level characteristics at baseline $(\mathrm{N}=6531)$

\begin{tabular}{|llllll|}
\hline & BI & CWS & BI+CWS & Control & P-value \\
& $\begin{array}{l}(\mathbf{N}=1,638) \\
\mathbf{n}(\%)\end{array}$ & $\begin{array}{l}\mathbf{N}=1,693) \\
\mathbf{n}(\%)\end{array}$ & $\begin{array}{l}\mathbf{N}=1,569) \\
\mathbf{n}(\%)\end{array}$ & $\begin{array}{l}\mathbf{N = 1 , 6 3 1 )} \\
\mathbf{n}(\%)\end{array}$ & \\
\hline Aboriginal and Torres Strait Islander & & & & & \\
\hline Yes & $120(7)$ & $128(8)$ & $170(11)$ & $132(8)$ & $<0.01$ \\
\hline No & $1,507(93)$ & $1,549(92)$ & $1,390(89)$ & $1,488(92)$ & \\
\hline English is primary language spoken at home & & & & & \\
\hline Yes & $1,414(87)$ & $1,444(85)$ & $1,380(88)$ & $1,426(88)$ & 0.12 \\
\hline No & $215(13)$ & $245(15)$ & $185(12)$ & $202(12)$ & \\
\hline Gender & & & & & \\
\hline Female & $658(40)$ & $729(43)$ & $807(51)$ & $803(49)$ & $<0.01$ \\
\hline Male & $980(60)$ & $964(57)$ & $762(49)$ & $828(51)$ & \\
\hline a P-values calculated by Fisher's Exact Test & & & & & \\
\hline
\end{tabular}

Unadjusted proportions for plain water (PW) weekly consumption (see Table 3) between baseline and follow-up indicate that while the consumption of $\geq 7$ cups on average per week increased across all groups, the largest change was seen among students receiving CWS, from $86 \%(n=1,424)$ at baseline to $90 \%(n=1,196)$ follow-up. Similarly, a beneficial reduction in SSB consumption was seen in all four groups, with the proportion of students reporting at Never/Rarely, increasing across all groups by at least $4 \%$ points. Of these, the greatest increase in this was seen among students receiving BI + CWS, with the unadjusted proportion increasing from $28 \%(n=426)$ to $35 \%(n=390)$. 
Table 3

Consumption (cups per week) of PW and SSBs.

\begin{tabular}{|c|c|c|c|c|c|c|c|c|c|c|c|c|}
\hline & \multicolumn{12}{|l|}{ Group } \\
\hline & \multicolumn{3}{|l|}{ BI } & \multicolumn{3}{|l|}{ cWs } & \multicolumn{3}{|l|}{$\mathrm{BI}+\mathrm{CWS}$} & \multicolumn{3}{|l|}{ Control } \\
\hline & $\begin{array}{l}\text { Baseline } \\
\text { N (\%) }\end{array}$ & $\begin{array}{l}\text { Post } \\
\mathrm{N} \\
(\%)\end{array}$ & $\begin{array}{l}\text { Follow- } \\
\text { up } \\
\mathrm{N}(\%)\end{array}$ & $\begin{array}{l}\text { Baseline } \\
\text { N (\%) }\end{array}$ & $\begin{array}{l}\text { Post } \\
\mathbf{N} \\
(\%)\end{array}$ & $\begin{array}{l}\text { Follow- } \\
\text { up } \\
\mathrm{N}(\%)\end{array}$ & $\begin{array}{l}\text { Baseline } \\
\mathbf{N}(\%)\end{array}$ & $\begin{array}{l}\text { Post } \\
\mathbf{N} \\
(\%)\end{array}$ & $\begin{array}{l}\text { Follow- } \\
\text { up } \\
\mathrm{N}(\%)\end{array}$ & $\begin{array}{l}\text { Baseline } \\
\mathbf{N}(\%)\end{array}$ & $\begin{array}{l}\text { Post } \\
\mathbf{N} \\
(\%)\end{array}$ & $\begin{array}{l}\text { Follow- } \\
\text { up } \\
\mathrm{N}(\%)\end{array}$ \\
\hline \multicolumn{13}{|l|}{ Plain water } \\
\hline Never/Rarely & $15(1)$ & $\begin{array}{l}13 \\
(1)\end{array}$ & $8(1)$ & $17(1)$ & $\begin{array}{l}25 \\
(2)\end{array}$ & $13(1)$ & $19(1)$ & $\begin{array}{l}19 \\
(2)\end{array}$ & $8(1)$ & $21(1)$ & $\begin{array}{l}15 \\
(1)\end{array}$ & $15(1)$ \\
\hline$\leq 1$ Cup & $36(2)$ & $\begin{array}{l}23 \\
(2)\end{array}$ & $20(1)$ & $34(2)$ & $\begin{array}{l}30 \\
(2)\end{array}$ & $19(1)$ & $34(2)$ & $\begin{array}{l}26 \\
(2)\end{array}$ & $18(2)$ & $26(2)$ & $\begin{array}{l}25 \\
(2)\end{array}$ & $20(2)$ \\
\hline 2-6 Cups & $157(10)$ & $\begin{array}{l}128 \\
\text { (9) }\end{array}$ & $116(9)$ & $178(11)$ & $\begin{array}{l}123 \\
(9)\end{array}$ & $106(8)$ & $175(11)$ & $\begin{array}{l}149 \\
(12)\end{array}$ & $\begin{array}{l}122 \\
(11)\end{array}$ & $201(13)$ & $\begin{array}{l}145 \\
(10)\end{array}$ & $\begin{array}{l}136 \\
(10)\end{array}$ \\
\hline$\geq 7$ Cups & $\begin{array}{l}1406 \\
(87)\end{array}$ & $\begin{array}{l}1237 \\
(88)\end{array}$ & $\begin{array}{l}1201 \\
(89)\end{array}$ & $\begin{array}{l}1424 \\
(86)\end{array}$ & $\begin{array}{l}1223 \\
(87)\end{array}$ & $\begin{array}{l}1196 \\
(90)\end{array}$ & $\begin{array}{l}1320 \\
(85)\end{array}$ & $\begin{array}{l}1062 \\
(85)\end{array}$ & $\begin{array}{l}980 \\
(87)\end{array}$ & $\begin{array}{l}1359 \\
(85)\end{array}$ & $\begin{array}{l}1294 \\
(87)\end{array}$ & $\begin{array}{l}1152 \\
(87)\end{array}$ \\
\hline \multicolumn{13}{|l|}{ SSB } \\
\hline Never/Rarely & $459(28)$ & $\begin{array}{l}461 \\
(33)\end{array}$ & $\begin{array}{l}435 \\
(32)\end{array}$ & $474(29)$ & $\begin{array}{l}441 \\
(31)\end{array}$ & $\begin{array}{l}432 \\
(33)\end{array}$ & $426(28)$ & $\begin{array}{l}403 \\
(32)\end{array}$ & $\begin{array}{l}390 \\
(35)\end{array}$ & $452(28)$ & $\begin{array}{l}451 \\
(31)\end{array}$ & $\begin{array}{l}418 \\
(32)\end{array}$ \\
\hline$\leq 1$ Cup & $533(33)$ & $\begin{array}{l}484 \\
(35)\end{array}$ & $\begin{array}{l}463 \\
(34)\end{array}$ & 559 (34) & $\begin{array}{l}438 \\
(31)\end{array}$ & $\begin{array}{l}457 \\
(34)\end{array}$ & $510(33)$ & $\begin{array}{l}404 \\
(32)\end{array}$ & $\begin{array}{l}344 \\
(31)\end{array}$ & 553 (34) & $\begin{array}{l}481 \\
(33)\end{array}$ & $\begin{array}{l}422 \\
(32)\end{array}$ \\
\hline 2-6 Cups & $463(29)$ & $\begin{array}{l}341 \\
(24)\end{array}$ & $\begin{array}{l}340 \\
(25)\end{array}$ & $443(27)$ & $\begin{array}{l}365 \\
(26)\end{array}$ & $\begin{array}{l}320 \\
(24)\end{array}$ & $404(26)$ & $\begin{array}{l}319 \\
(25)\end{array}$ & $\begin{array}{l}289 \\
(26)\end{array}$ & 433 (27) & $\begin{array}{l}394 \\
\text { (27) }\end{array}$ & $\begin{array}{l}340 \\
(26)\end{array}$ \\
\hline$\geq 7$ Cups & $161(10)$ & $\begin{array}{l}116 \\
(8)\end{array}$ & $110(8)$ & $178(11)$ & $\begin{array}{l}157 \\
(11)\end{array}$ & $120(9)$ & 207 (13) & $\begin{array}{l}131 \\
(10)\end{array}$ & $97(9)$ & $167(10)$ & $\begin{array}{l}146 \\
(10)\end{array}$ & $\begin{array}{l}142 \\
(11)\end{array}$ \\
\hline
\end{tabular}

To quantify the individual and joint effects of TCW-BI and CWS on the consumption of water and SSBs, random effects multivariable ordinal logistic regression models were derived for each outcome. In addition to gender and LHD being forced into these models due to potential confounding, other school- and student-level model candidate covariates were identified by the use of univariable analysis, followed by manual backward stepwise elimination (see Supplementary Tables 1a and 1b). Students were more likely to consume higher levels of water if they were enrolled at a school with a middle or high ICSEA score, did not identify as Aboriginal and Torres Strait Islander, spoke English predominately at home, female, and usually consumed water in various settings (e.g. during social activities). As for SSBs, higher levels of consumption were more likely if students were enrolled at a school with a low ICSEA score and the canteen was leased. At the student-level, higher SSB consumption was more likely amongst students who were Aboriginal and Torres Strait Islander, male and usually consumed SSB in a variety of settings such as during exercise or sport, home meals, school, screen time and social activities.

Table 4 presents the individual effects of $\mathrm{BI}$, CWS and their joint effect on the consumption of PW and SSB between baseline and follow-up. For students who received at least one intervention, the increased odds of higher water consumption, compared to those who received none, ranged between $5 \%$ and $48 \%$. However, these increases were not found to be statistically significant at the $5 \%$ level. A subgroup analysis on the consumption of PW, stratified by LHD indicated that the joint effect of $\mathrm{BI}$ and CWS, though not statistically significant, was larger for LHD1 students when compared to students enrolled in either of the two other LHD's. Furthermore, and given that the loss to follow-up was more substantial in LHD-1 when compared to the two other LHDs (see Supplementary Table 2a), it is likely that the magnitude of the joint effect was by consequence, reduced to a level below those of each individual intervention.

Conversely, and compared to students in the control group, students who received at least one intervention were more likely to decrease their consumption of SSB. But, only for those receiving both interventions was this reduction, being $33 \%$, found to be statistically significant ( $<<$ 0.01). When stratified by gender (see Supplementary Tables $2 \mathrm{~b}$ and $2 \mathrm{c}$ ), male students in the CWS group were found to significantly increase their water consumption (OR: $2.11 ; 95 \% \mathrm{Cl}: 1.21-3.66 ; \mathrm{p}=0.01$ ), unlike female students, for which no significant effect was detected.

Additionally, male students in the combined intervention group were found to statistically decrease their SSB consumption (OR: $0.59 ; 95 \% \mathrm{Cl}$ : 0.44-0.79; $p$ <.01). While SSB consumption among female students who received the BI and CWS was seen to decrease (OR: 0.58-1.03), this reduction was no longer statistically significant, unlike the case for all students. 
Table 4

Individual and joint intervention effects on weekly PW and SSBs consumption between baseline and follow-up

\begin{tabular}{|lllllll|}
\hline Intervention Effect & PW & \multicolumn{5}{c|}{ SSB } \\
& OR & $95 \% \mathrm{Cl}$ & P-value & OR & $95 \% \mathrm{Cl}$ & P-value \\
\hline BI without CWS & 1.27 & $0.86-1.87$ & 0.23 & 0.86 & $0.70-1.06$ & 0.17 \\
\hline CWS without BI & 1.48 & $0.97-2.24$ & 0.07 & 0.87 & $0.69-1.08$ & 0.20 \\
\hline BI + CWS & 1.05 & $0.71-1.55$ & 0.80 & 0.67 & $0.55-0.82$ & $<0.01$ \\
\hline
\end{tabular}

\section{Discussion}

The Thirsty? Choose Water! study aimed to examine the impact of two interventions, alone or combined on year 7 students' water consumption and SSB consumption. This paper demonstrates the positive outcomes of these interventions and that these changes in knowledge and attitude have translated to changed consumption behaviours. Whilst the change was not statistically significant, students who received at least one intervention did demonstrate an increased odds of higher water consumption, compared to those who received none. Additionally, students who received at least one intervention were more likely to decrease their consumption of SSB. For those students who received both interventions the reduction in SSBs was statistically significant.

These results are consistent with a number of other studies that have examined the impacts of water and SSB interventions. In the context of reducing SSBs, a 2017 systematic review demonstrated that educational interventions alone had success rates of $65 \%$ and those that combined legislative/environmental change were slightly more successful (66.7\%). ${ }^{13}$ In the context of increasing water consumption, whilst changes in this study did not reach significance, current evidence does suggest that the inclusion of both educational/behavioural and legislative and environmental interventions are important to achieve a significant effect of increasing water consumption. ${ }^{10}$ Additionally, despite the expectation that increasing water consumption displaces SSBs, interventions that focus only on promoting water consumption, have been shown to have limited impact on reducing SSBs. In the context of this literature, findings of the current study also lend support to the need for multicomponent interventions. It would appear that the combination of an environmental intervention with an educational intervention adds value, by allowing students to act on their new knowledge about the detriment of SSBs and the benefits of water, and with access to a CWS reduce their SSB consumption.

In this study SSB consumption is consistent with other Australian data that shows SSB consumption is higher in different population subgroups including low SES populations, among males and Aboriginal populations. ${ }^{23}$ In this sample, SSB consumption was also higher in schools with leased canteens.

\section{Strengths and Limitations}

This study has a number of strengths that address gaps identified in the literature. Researchers had identified the need for stronger study designs that include a power calculation, allow for longer term follow-up and measures that include a combination of validated self-reported and objective measures of water consumption, ${ }^{10}$ and that test interventions alone or combined. ${ }^{12}$ This study has addressed all of these concerns. Furthermore, Moghadam et al (2019) suggest that 'a randomized controlled trial that uses a factorial design to examine the independent and combined effects of water promotion and SSB reduction strategies on both water and SSB consumption and/or purchases would be a useful addition to the literature.'11 This study has achieved this, adding a valuable contribution to demonstrate effective strategies to address water and SSB consumption and the interaction and synergy of these interventions.

Whilst the study collected 'soft-data' (self-report responses) on baseline water consumption data, 'hard data' (objective measurement) was not gathered and could be seen as a limitation of the study. Collecting this objective measurement would have necessitated measuring water consumption across all water sources in a school, with the provision and installation of data loggers for this purpose beyond the scope of the study budget. An additional limitation is the manner in which self-report water consumption data was collected. This was through the validated SPANS question on beverage consumption; however, the use of the Likert scale was limiting, as at baseline students already reported high levels of water consumption. The Likert scale was unable to detect any increase in self-reported water consumption, and in future studies it is recommended this information is collected as continuous data, by asking students how many cups of water they drink each day.

\section{Conclusion}


To our knowledge, this is the first Australian study to test two interventions within a factorial design to promote water consumption and decrease SSB consumption. Furthermore, this study is unique in that it tests the installation of CWS in a school setting as a mechanism to increase water consumption and decrease SSB consumption in secondary school students. The findings of the study demonstrate that both interventions alone or combined are effective. Students in the TCW-BI and CWS intervention groups showed changes in SSB consumption, and whilst there was not a statistically significant result seen in the interventions alone, this was seen when the interventions were combined. Similarly the interventions either alone or combined did have a beneficial effect on water consumption, but these effects were not statistically significant, possibly due to the limitation in the way self-reported water consumption was recorded. Nevertheless, these findings add strong evidence of effective school based strategies to encourage adolescent to choose water instead of SSBs. Further work is required to determine how these interventions can be delivered at scale; what support schools and immunisation nurses would require to deliver the TCW-BI implementation in a sustainable way; and what policy makers would require to progress the wide-spread installation of CWS in secondary schools. A future economic analysis of this study may contribute to achieving this goal, by assessing the costs of the intervention against the outcomes.

\section{Abbreviations}

CWS Chilled water station

ICSEA Index of Community Socio-Educational Advantage

LHDs Local Health Districts

NSW New South Wales

PDHPE Personal Development, Health and Physical Activity

PW Plain Water

SSB sugar sweetened beverages

SERAP State Education Research Applications Process

SPANS Schools Physical Activity and Nutrition Survey

TCW-BI Thirsty? Choose Water! Behavioural Intervention

\section{Declarations}

\section{Ethics approval and consent to participate:}

Ethics approval was obtained from the Hunter New England Human Research Ethics Committee (17/08/16/4.07), the NSW Department of Education (SERAP2017457) and Broken Bay, Sydney and Wollongong Catholic Diocese. Consent to participate in the study is provided at the school level by school principals. Participation of students in the evaluation component of the study was through an opt-out consent process, where parents provided written documentation to state they did not wish for their child to participate in the evaluation. This opt-out consent process approach was approved by all the above ethical reviews, with the exception of the Sydney Catholic Diocese. Participating schools within this Diocese required written informed consent from parents for their child to participate in the evaluation component, and this requirement was met by the study.

\section{Consent for publication:}

Not applicable

\section{Availability of data and material:}

Not applicable

\section{Competing interests:}

The authors declare that they have no competing interests

Funding: 
Funding for this study was secured through the NSW Ministry of Health Translational Research Grants for a 2 year period from 2017-2019. Through this funding submission process the study underwent a thorough peer review process. Funding covered staffing costs for study implementation and evaluation as well as resource costs related to the behavioural and chilled water station intervention.

\section{Authors'contributions:}

NK made substantial contributions to conception and design of the study and as the principal investigator was accountable for all aspects of the study and secured funding for the study. JG made contributions to the conception and design of the initial pilot project and the broader Thirsty Choose Water study and is the project coordinator for the study. MD is responsible for the study design and statistical analysis and is a key contributor to the manuscript. PL has contributed to study development and design and review of manuscript. SB drafted the manuscript in collaboration with fellow authors.

All authors read, revised and approved the final manuscript.

\section{Acknowledgments:}

We would like to acknowledge the 61 school communities - staff and students, Infrastructure NSW Asset Managers and Senior Officers, the Thirsty? Choose Water! Advisory Group Members and ISLHD Health Promotion Service \& Public Health Unit and SWSLHD Health Promotion Service \& Public Health Unit for assistance in implementing the study.

\section{References}

1. Australian Bureau of Statistics. National Health Survey, First Results, 2017-18. Canberra: Commonwealth of Australia; 2018.

2. Bleich SN, Vercammen KA. The negative impact of sugar-sweetened beverages on children's health: an update of the literature. BMC Obesity. 2018;5(6).

3. Deren K, Weghuber D, Caroli M, Koletzko B, Thivel D, Frelut ML, et al. Consumption of Sugar-Sweetened Beverages in Paediatric Age: A Position Paper of the European Academy of Paediatrics and the European Childhood Obesity Group. Ann Nutr Metab. 2019;74(4):296302.

4. Scully M, Morley B, Niven P, Crawford D, Pratt IS, Wakefield M. Factors associated with high consumption of soft drinks among Australian secondary-school students. Public Health Nutr. 2017;20(13):2340-8.

5. Centre for Epidemiology and Evidence. New South Wales School Students Health Behaviours Survey: 2011 Report. Sydney: NSW Ministry of Health; 2013.

6. Langford R, Bonell C, Jones H, Pouliou T, Murphy S, Waters E, et al. The World Health Organization's Health Promoting Schools framework: a Cochrane systematic review and meta-analysis. BMC Public Health. 2015;15(1):130.

7. Zheng M, Rangan A, Olsen NJ, Andersen LB, Wedderkopp N, Kristensen P, et al. Substituting sugar-sweetened beverages with water or milk is inversely associated with body fatness development from childhood to adolescence. Nutrition. 2015;31(1):38-44.

8. Muckelbauer R, Gortmaker SL, Libuda L, Kersting M, Clausen K, Adelberger B, et al. Changes in water and sugar-containing beverage consumption and body weight outcomes in children. Br J Nutr. 2016;115(11):2057-66.

9. Cradock AL, Everett Jones S, Merlo C. Examining differences in the implementation of school water-quality practices and water-access policies by school demographic characteristics. Prev Med Rep. 2019;14:100823.

10. Vezina-Im LA, Beaulieu D. Determinants and Interventions to Promote Water Consumption Among Adolescents: a Review of the Recent Literature. Curr Nutr Rep. 2019;8(2):129-44.

11. Dibay Moghadam S, Krieger JW, Louden DKN. A Systematic Review of the Effectiveness of Promoting Water Intake to Reduce Sugarsweetened Beverage Consumption. Obesity Science \& Practice. 2019.

12. Abdel Rahman A, Jomaa L, Kahale LA, Adair P, Pine C. Effectiveness of behavioral interventions to reduce the intake of sugar-sweetened beverages in children and adolescents: a systematic review and meta-analysis. Nutr Rev. 2018;76(2):88-107.

13. Vezina-Im LA, Beaulieu D, Belanger-Gravel A, Boucher D, Sirois C, Dugas M, et al. Efficacy of school-based interventions aimed at decreasing sugar-sweetened beverage consumption among adolescents: a systematic review. Public Health Nutr. 2017;20(13):2416-31.

14. Vargas-Garcia EJ, Evans CEL, Prestwich A, Sykes-Muskett BJ, Hooson J, Cade JE. Interventions to reduce consumption of sugarsweetened beverages or increase water intake: evidence from a systematic review and meta-analysis. Obes Rev. 2017;18(11):1350-63.

15. World Health Organization. Promoting Health Through Schools - Report of a WHO Expert Committee on Comprehensive School Health Education and Promotion. Geneva: World health Organization; 1997. 
16. Kenney EL, Gortmaker SL, Cohen JF, Rimm EB, Cradock AL. Limited School Drinking Water Access for Youth. J Adolesc Health. 2016;59(1):24-9.

17. Patel Al, Bogart LM, Klein DJ, Cowgill B, Uyeda KE, Hawes-Dawson J, et al. Middle School Student Attitudes About School Drinking Fountains and Water Intake. Acad Pediatr. 2014;14(5).

18. Onufrak SJ, Park S, Sharkey JR, Merlo C, Dean WR, Sherry B. Perceptions of tap water and school water fountains and association with intake of plain water and sugar-sweetened beverages. J Sch Health. 2014;84(3):195-204.

19. Kajons N, David M, Gowland-Ella J, Lewis P, Batchelor S. Thirsty? Choose Water! Behavioural interventions and water stations in secondary schools a two-by-two factorial randomised controlled trial. BMC Public Health. 2018;18(1):788.

20. Hardy L, Mihrshahi S, Drayton B, Bauman A. NSW Schools Physical Activity and Nutrition Survey (SPANS) 2015: Full Report. Sydney: NSW Department of Health; 2016.

21. Brant R. Assessing proportionality in the proportional odds model for ordinal logistic regression. Biometrics. 1990;46(4):1171-78.

22. Pregibon D. Goodness of link tests for generalized linear models. Applied Statistics. 1980;29(1):15-24.

23. Australian Bureau of Statistics. Australian Health Survey: Nutrition First Results - Foods and Nutrients, 2011-12. Consumption of Sweetened Beverages. 2015.

\section{Figures}

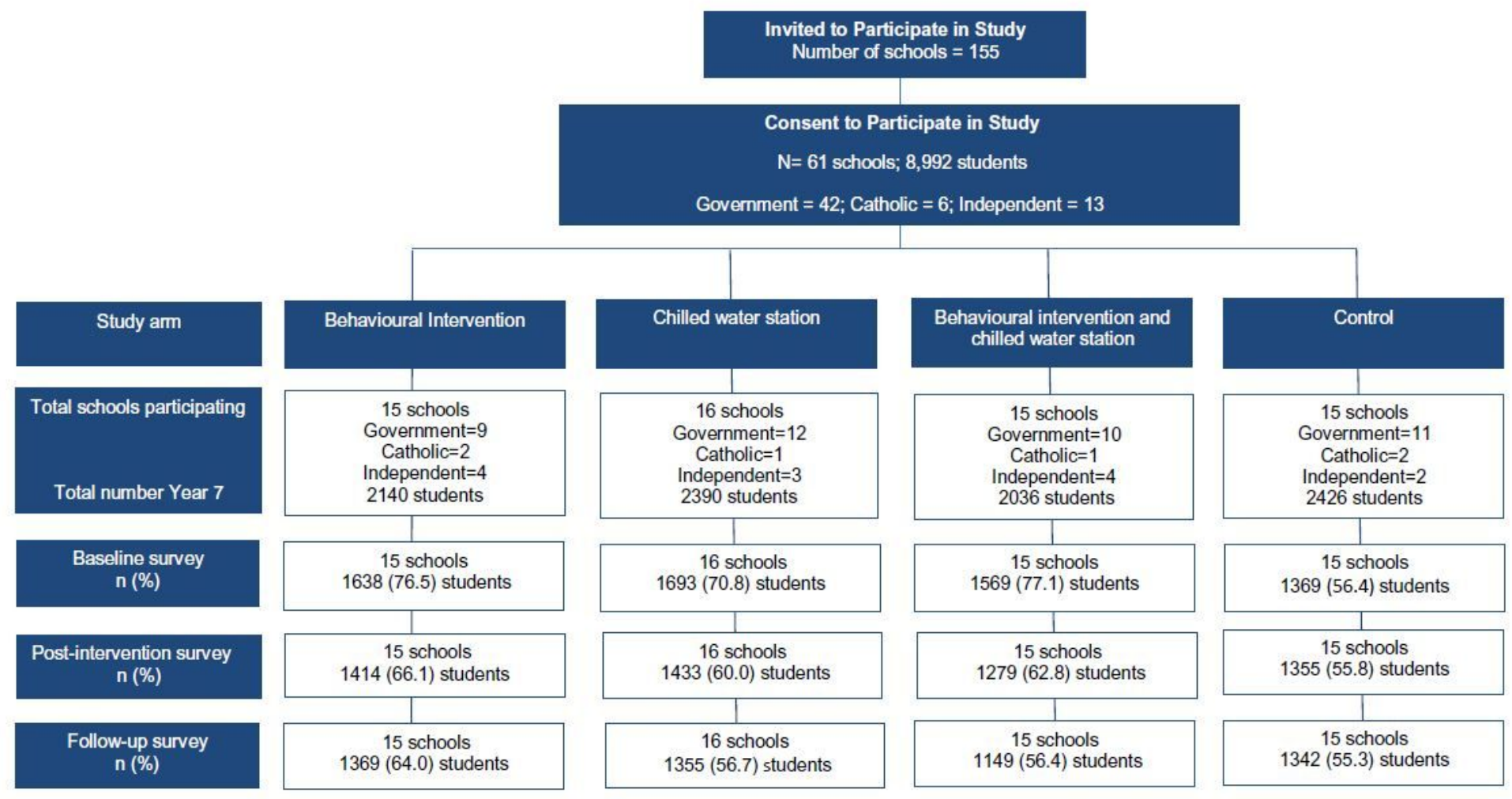

Figure 1

Flowchart of Thirsty? Choose Water! study - Schools and students

\section{Supplementary Files}

This is a list of supplementary files associated with this preprint. Click to download.

- SupplementaryTable1a.docx

- CONSORT2010ChecklistForTCW16September2020.doc 